\title{
Articles
}

\section{Structural and Conformational Studies of ortho-, meta-, and para-Methyl Red upon Proton Gain and Loss}

\author{
Sun-Kyung Park, ${ }^{\dagger}$ Choongkeun Lee, Kyung-Chul Min, and Nam-Soo Lee ${ }^{*}$ \\ Department of Chemistry, Chungbuk National University, Cheongju 361-763, Korea. *E-mail: nslee@chungbuk.ac.kr \\ ${ }^{\dagger}$ Thin Film Materials Laboratory, Advanced Materials Division, Korea Research Institute of Chemical Technology, \\ Yuseong P. O. Box 107, Daejeon 305-600, Korea \\ Received April 13, 2005
}

\begin{abstract}
The structures and conformations of ortho-, meta-, and para-methyl red (MR) upon proton gain and loss were studied by density functional calculations, and compared to methyl yellow for the effects of a carboxyl substitution. Internal hydrogen bonding causes the geometry of neutral $o$-MR planar, otherwise twist. Monoprotonated species of MR are planar where the proton is attached to $\beta$-azo nitrogen. This loses its azo character a bit, and shows strong delocalization characterized as a quinonoid canonical structure. Di-protonated species of MR is proved to hold two protons at the amino and $\alpha$-azo nitrogen atoms, and planar. It regains somewhat of its azo character, but still shows fairly delocalized property in terms of carbocationic canonical structures. The carboxyl substitution on 4-dimethylamino-trans-azobenzene structure has some delocalization effects on the geometry or conformation of MR derivatives whether neutral, mono-, di- or de-protonated.
\end{abstract}

Key Words : Methyl red, Protonation, Conformation, Density functional theory

\section{Introduction}

Methyl red (MR) derivatives are representative compounds of 4-amino-trans-azobenzene derivatives, and have been widely utilized as dyes, coloring agents, acid-base indicators implementing proton-transfer reactions, and electrochemical species exercising electron-transfer reactions etc. ${ }^{1}$ Property of light-induced reorientation in MR expanded its applicability to the fields of the dye-doped optoelectronics devices and the photochemical phase transitions between liquid crystalline and isotropic phase recently. ${ }^{2-8}$ It takes up the molecular properties of conformational changes from trans to cis conformer upon visible light irradiation shorter than $590 \mathrm{~nm}$ and consequent spontaneous relaxation to trans conformer and simultaneous reorientation processes. The geometry of MR derivative in trans conformer had been investigated by X-ray crystallographic study, ${ }^{9-11}$ which yielded a crystalline structure of non-planar azobenzene moiety. The dihedral angle between two substituted benzene rings was obtained to be 11.8 degrees. The planarity of MR in trans conformer was referred because it has a proton in its molecular structure which could make an intra-molecular hydrogen bonding. Two structural isomers of MR $(o-\mathrm{MR}$ and $p$-MR) showed a significantly different diffusivity in hydrogen bonding media. ${ }^{12,13}$ The diffusivity of $p$-MR was much lower than of $o-\mathrm{MR}$ in hydrogen-bonding polymer solutions while these two isomers showed a similar diffusivity in non-hydrogen-bonding media. The difference was attributed to the internal hydrogen-bonding in $o$-MR between the carboxyl proton and the azo nitrogen atom. The internal hydrogen-bonding of the carboxyl hydrogen had weakened the external hydrogen-bonding of $o$-MR to the polymer chains. ${ }^{14}$

MR changes its color on protonation or de-protonation. In acidic solutions, the protonation was known to be in equilibrium of the protonated azo form with absorption of about $500 \mathrm{~nm}$ and the colorless ammonium cationic form. The protonated azo form could have a resonance structure of the quinonoid which is responsible for the red shift from about $460 \mathrm{~nm}$ absorption of neutral MR. On protonation at one of the azo nitrogens or amine nitrogen, the azo group and benzene ring moieties are predicted to resettle in electronic structure of molecules. ${ }^{15-17}$ The Raman spectra in solid state of neutral, de-protonated (anionic), monoprotonated (monocationic) and di-protonated (dicationic) species of MR derivatives differ markedly in vibrational spectroscopic features, ${ }^{18}$ mainly due to the changes in molecular and electronic structure which occur upon proton gain and loss.

The structural and conformational features of protonated MR species have not been fully clarified yet. Especially, the di-protonated species of MR derivatives in strong acid media had not received much attention. Each derivative species of MR has three nitrogen atoms, N(7), N(10) and $\mathrm{N}(12)$ as shown in Figure 1 represented for the case of $o$ $\mathrm{MR}$, and each of them can be a potential protonation site. Thus there are three possible types of mono-protonated dye molecule. ${ }^{19}$ For di-protonated MR dye species, three types are possible, i.e., at $\mathrm{N}(7)$ and $\mathrm{N}(10)$, at $\mathrm{N}(7)$ and $\mathrm{N}(12)$ and at $\mathrm{N}(12)$ and $\mathrm{N}(10)$. From the isotope substitution studies by 


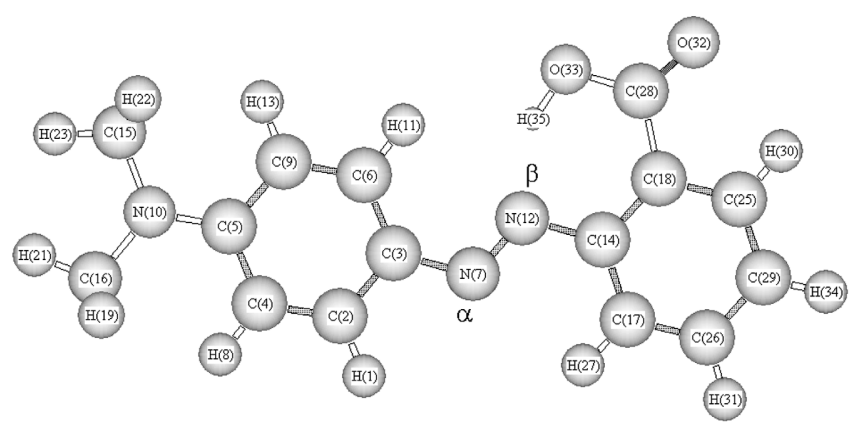

Figure 1. Chemical structure of neutral $o-\mathrm{MR}$ with intramolecular hydrogen bonding and the index numbers with specifying positions of $\alpha$ - and $\beta$-nitrogen.

resonance Raman and NMR spectroscopic methods, methyl orange and 4-aminoazobenzene were revealed to take the dicationic azo form protonated at the dimethylamino and the $\alpha$-azo nitrogens. ( $\alpha$-Azo nitrogen atom corresponds to $\mathrm{N}(7)$ atom in Figure 1 for $o$-MR. $)^{20,21}$ For another class of aromatic azo dye, Tropaeolin $\mathrm{O}$, the protonated hydrazone form was proposed, in contrast. However, this form was excluded for methyl orange or 4-aminoazobenzene from experimental spectroscopic results.

In this paper, the calculation studies of azo dyes upon proton gain and loss have been investigated in the conformational, structural and energetic points of view by density functional theory (BP86 and B3LYP). ${ }^{22}$ The hybrid functional BP86 was proved to explicate well the structural and vibrational features of, in particular, azobenene species. ${ }^{23}$ Also, another hybrid method B3LYP has been employed with good satisfaction in neutral and charged species when applied using polarized basis sets along with diffuse functions. ${ }^{24}$ For neutral MR species, there are two different orientations of carboxyl group of ortho- position on a benzene ring of azobenzene moiety in MR derivatives. The intra-molecular hydrogen binding capabilities for both conformers would be evaluated for the conformation of neutral MR, protonated MR, and di-protonated MR species. Also, the protonation sites would be clarified for protonated and di-protonated MR species by the computing method. By comparing three geometric isomers, i.e., ortho-, meta-, and para-MR derivatives, the substitution effects of carboxyl group on benzene ring would be associated. In addition, the conformation and structure of methyl yellow species were calculated to examine any influence of carboxyl group substitution on the ring.

\section{Calculation Methods}

Initial chemical structures of MR species were generated using CS CHEM3D PRO (CambridgeSoft Cooperation) and transferred to the Gaussian package G03W (Gaussian, Inc. $)^{25}$ for the optimization and the frequency calculation to obtain thermochemical properties at the higher levels. The energies of fully optimized conformers or species were obtained at BP86 and B3LYP levels using 6-31G** and 6-
$31+\mathrm{G}^{*}$ basis sets. The temperature was set to $298.15 \mathrm{~K}$ and the pressure to $1.0 \mathrm{~atm}$, and any scaling factor for the frequency calculations was not applied. The thermodynamic energies of MR derivatives (MR for neutral, MRA for anionic, MRH for monocationic, and MRHH for dicationic) in the vapor phase were calculated from geometries optimized. For comparison, methyl yellow (MY) which lacks carboxyl group in chemical structure was calculated in the same manner for the species MY, MYA, MYH, and MYHH as carried out for MR species. The conformation of the global minimum energy for each species was chosen to be the stable conformation. The electronic energies added with zero-point correction $\left(\Delta \mathrm{E}_{\mathrm{c}}\right)$ at $0 \mathrm{~K}$ and the summation of electronic and thermal free energies $\left(\Delta \mathrm{G}_{\mathrm{T}}\right)$ at $298 \mathrm{~K}$ were obtained in Hartree unit. The dihedral angles of azobenzene moiety around the $\mathrm{N}=\mathrm{N}$ bond were obtained from fully optimized conformations.

\section{Results and Discussion}

Conformations of neutral $\boldsymbol{o}$-MR. We may configure six different conformers possible for neutral $o$-MR species as shown in the bottom of Table 1. Electronic energies $\Delta \mathrm{E}_{\mathrm{c}}$ corrected with zero-point energy and thermal free energies $\Delta \mathrm{G}_{\mathrm{T}}$ at $298 \mathrm{~K}$ are listed in Hartree unit, along with the dihedral angles (here, to examine co-planarity of two benzene rings) defined of $\mathrm{C}(6)-\mathrm{C}(3)-\mathrm{C}(14)-\mathrm{C}(18)$ (cf. Figure 1) in degree unit, and the distances of the $\mathrm{N}=\mathrm{N}$ bonds $\Delta \mathrm{r}$ in $\AA$ unit in Table 1. For convenience in thermal free energies, relative energies $\left(\Delta \Delta \mathrm{G}_{\mathrm{T}}\right)$ to conformer $\mathbf{1}$ which is the lowest are listed in $\mathrm{kcal} / \mathrm{mol}$ unit. The distance of $\mathrm{N}=\mathrm{N}$ bond of conformer 1 has come out to be $1.266 \AA$ and others $1.263 \AA$ under B3LYP method, on the other hand a bit longer under BP86 method. These are in good agreement with that obtained from the crystal structure, $1.268 \AA .^{9 a}$ Among them, conformer 1 or 6 could form an intra-molecular hydrogen bond between a carboxyl proton and an azo nitrogen atom. Both geometries are optimized to be planar and others twist about $30^{\circ}$ under two different methods. In the case of conformer $\mathbf{6}$, the hydrogen bonding is obviously weaker than conformer $\mathbf{1}$ because it could form a seven-member ring structure via hydrogen bonding as seen. The molecular planarity, the energetics or an extension of $\mathrm{N}=\mathrm{N}$ bond due to an internal hydrogen bonding confirms that molecular $\pi$ electrons be delocalized favorably across the whole molecular system.

Conformers 2 and 4 are associated with each other a rotamer about $\mathrm{N}(12)-\mathrm{C}(14)$ bond, and the same as for conformers 3 and 5. Conformers 2 and 3 are regarded as pseudo-trans geometry via the connection of $\mathrm{N}=\mathrm{N}-\mathrm{C}-\mathrm{C}_{\alpha}$, but conformers 4 and 5 as pseudo-cis where $\mathrm{C}_{\alpha}$ denotes a carbon atom attached by a carboxyl group. In rotamers of these kinds, pseudo-trans conformer is lower about $1 \mathrm{kcal} / \mathrm{mol}$ than pseudo-cis as seen in Table 1. These four conformers are all twist about $30^{\circ}$, presumably due to the electronic repulsion between unpaired electrons nearby. The planarity of 4-amino-trans-azobenene derivatives had been investi- 
Table 1. $\Delta \mathrm{E}_{\mathrm{c}}$ and $\Delta \mathrm{G}_{\mathrm{T}}$, DA (Dihedral angles of $\mathrm{C}(6)-\mathrm{C}(3)-\mathrm{C}(14)-$ $\mathrm{C}(18))$ in degree unit, and $\Delta \mathrm{r}(\mathrm{N}=\mathrm{N})$ in $\AA$ unit obtained from geometries optimized at the levels of B3LYP/6-31+G* and BP86/ $6-31+\mathrm{G}^{*}$ for various conformations of neutral $o-\mathrm{MR} .\left(\Delta \Delta \mathrm{G}_{\mathrm{T}}\right.$ in $\mathrm{kcal} / \mathrm{mol}$ )

\begin{tabular}{|c|c|c|c|c|c|c|}
\hline \multirow{2}{*}{$\begin{array}{c}\text { Confor- } \\
\text { mer }\end{array}$} & \multicolumn{3}{|c|}{ B3LYP/6-31+G* } & \multicolumn{3}{|c|}{ BP86/6-31+G* } \\
\hline & $\begin{array}{l}\Delta \mathrm{E}_{\mathrm{c}} \\
\Delta \mathrm{G}_{\mathrm{T}}\end{array}$ & $\Delta \Delta \mathrm{G}_{\mathrm{T}}$ & $\begin{array}{l}\mathrm{DA} /{ }^{\circ} \\
\Delta \mathrm{r} / \AA\end{array}$ & $\begin{array}{l}\mathrm{DE}_{\mathrm{c}} \\
\Delta \mathrm{G}_{\mathrm{T}}\end{array}$ & $\Delta \Delta \mathrm{G}_{\mathrm{T}}$ & $\begin{array}{l}\mathrm{DA} /{ }^{\circ} \\
\Delta \mathrm{r} / \AA\end{array}$ \\
\hline \multirow[t]{2}{*}{1} & -895.060789 & & 0.0 & -895.074542 & & 0.0 \\
\hline & -895.109748 & $\mathbf{0}$ & 1.266 & -895.123729 & $\mathbf{0}$ & 1.286 \\
\hline \multirow[t]{2}{*}{2} & -895.052756 & & 28.5 & -895.063528 & & 30.2 \\
\hline & -895.102142 & 4.8 & 1.263 & -895.113062 & 6.7 & 1.283 \\
\hline \multirow[t]{2}{*}{3} & -895.052614 & & 30.4 & -895.063415 & & 28.7 \\
\hline & -895.101974 & 4.9 & 1.263 & -895.112788 & 6.9 & 1.283 \\
\hline \multirow[t]{2}{*}{4} & -895.051564 & & 31.2 & -895.062372 & & 30.7 \\
\hline & -895.100295 & 5.9 & 1.263 & -895.111278 & 7.8 & 1.283 \\
\hline \multirow[t]{2}{*}{5} & -895.050242 & & 33.2 & -895.061165 & & 31.7 \\
\hline & -895.099209 & 6.6 & 1.263 & -895.110149 & 8.5 & 1.282 \\
\hline \multirow[t]{2}{*}{6} & -895.052997 & & 0.0 & -895.068027 & & 0.0 \\
\hline & -895.101712 & 5.0 & 1.263 & -895.116736 & 4.4 & 1.283 \\
\hline
\end{tabular}

$\Delta \mathrm{E}_{\mathrm{c}}$ : summation of electronic and zero-point energies/Hartree. $\Delta \mathrm{G}_{\mathrm{T}}$ : summation of electronic and thermal free energies/Hartree

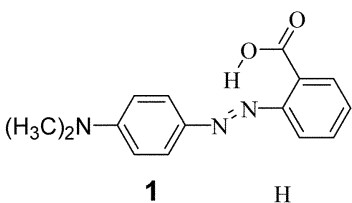

1<smiles>CN(C)c1ccc(N=Nc2ccccc2C(=O)O)cc1</smiles>
3<smiles>CN(C)c1ccc(N=Nc2ccccc2C(=O)O)cc1</smiles>

gated in crystallography, spectroscopy or theoretical calculation disciplines. Previous results were split to planar $^{9 b}$ or twist ${ }^{9 \mathrm{a}}$ upon methods and/or 4-aminoazobenzene derivatives applied. This implies that an intra- or intermolecular hydrogen bonding could play a role for the molecular structure to reorient and develop its molecular planarity.

Conformations of anionic MRA isomers. Calculated results of de-protonated anionic species of $o$-MRA, $m$-MRA, and $p$-MRA are listed in Table 2 and Table 3 , the distances of $\mathrm{N}=\mathrm{N}$ bonds and dihedral angles, and the energetic data. There are two conformers upon substitution of a carboxyl group, $\mathrm{C}(18)$ or $\mathrm{C}(17)$ for $o$-MRA and $\mathrm{C}(25)$ or $\mathrm{C}(26)$ for $m$ MRA. For $o$-MRA (cf. Figure 1), the distance of $\mathrm{N}=\mathrm{N}$ bond has been contracted a little from neutral and twist about $30^{\circ}$ for which carboxyl group is attached to $C(18)$, and less for $\mathrm{C}(17)$. But, the bond length is not much changed (1.264 $\AA$ to $1.263 \AA$ ) for m-MRA in both substitutions and almost planar. This is partly because a carboxyl group behaves typically as a meta-director in the substitution reaction on a

Table 2. DA (Dihedral angles of C(6)-C(3)-C(14)-C(18)) in degree unit, $\Delta \mathrm{r}(\mathrm{N}=\mathrm{N})$ in $\AA$ unit for deprotonated (MRA), neutral (MR), momo-(MRH), and di-protonated (MRHH) species of $o-\mathrm{MR}, m-$ MR, $p$-MR and MY. (More stable rotamers are written in Bold.)

\begin{tabular}{|c|c|c|c|c|c|c|c|c|}
\hline \multirow{2}{*}{\multicolumn{3}{|c|}{ B3LYP/6-31+G* }} & \multirow{2}{*}{\multicolumn{2}{|c|}{$\frac{o-\mathrm{MR}}{\mathrm{C}(18)-\mathrm{C}(17)-}$}} & \multicolumn{2}{|c|}{$m$-MR } & \multirow{2}{*}{$p$-MR } & \multirow{2}{*}{ MY } \\
\hline & & & & & $C(25)-$ & $C(26)-$ & & \\
\hline \multirow{2}{*}{ MRA } & & DA & 26.6 & 18.8 & -0.6 & 1.6 & 1.6 & - \\
\hline & & $\Delta \mathrm{r}$ & 1.258 & 1.260 & 1.263 & 1.262 & 1.265 & - \\
\hline & & 0.0 & 0.0 & 0.0 & 0.0 & 0.0 & 0.0 \\
\hline & & $\Delta \mathrm{r}$ & 1.266 & 1.263 & 1.264 & 1.264 & 1.266 & 1.263 \\
\hline \multirow{4}{*}{$\mathrm{R}$} & B & DA & 0.0 & -58.6 & 0.0 & 0.0 & 0.0 & 0.0 \\
\hline & & $\Delta \mathrm{r}$ & 1.289 & 1.286 & 1.286 & 1.286 & 1.287 & 1.285 \\
\hline & 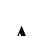 & DA & -48.2 & 0.0 & 0.0 & 0.7 & 19.9 & -15.3 \\
\hline & & $\Delta \mathrm{r}$ & 1.273 & 1.278 & 1.277 & 1.278 & 1.279 & 1.278 \\
\hline \multirow{4}{*}{ IRH } & Y & DA & -20.6 & 0.0 & 0.0 & 0.0 & 0.0 & 0.0 \\
\hline & & $\Delta \mathrm{r}$ & 1.268 & 1.268 & 1.275 & 1.275 & 1.276 & 1.278 \\
\hline & $\mathbf{X}$ & DA & 0.0 & -45.4 & 0.0 & 0.5 & 14.5 & 17.6 \\
\hline & & $\Delta \mathrm{r}$ & 1.263 & 1.265 & 1.265 & 1.265 & 1.266 & 1.267 \\
\hline \multirow{2}{*}{\multicolumn{3}{|c|}{ BP86/6-31+G* }} & \multicolumn{2}{|c|}{$o-\mathrm{MR}$} & \multicolumn{2}{|c|}{$m$-MR } & \multirow{2}{*}{$p$-MR } & \multirow{2}{*}{ MY } \\
\hline & & & $C(18)-$ & $C(17)-$ & $C(25)-$ & $C(26)-$ & & \\
\hline \multirow{2}{*}{ MRA } & & DA & 35.4 & 3.4 & -0.5 & 4.9 & 2.8 & - \\
\hline & & $\Delta \mathrm{r}$ & 1.283 & 1.283 & 1.283 & 1.282 & 1.290 & - \\
\hline \multirow{2}{*}{\multicolumn{2}{|c|}{ MR }} & DA & 0.0 & 0.0 & 0.0 & 0.0 & 0.0 & 0.0 \\
\hline & & $\Delta r$ & 1.286 & 1.283 & 1.284 & 1.283 & 1.286 & 1.283 \\
\hline \multirow{4}{*}{ MRH } & & DA & 0.0 & -50.8 & 0.0 & 0.0 & 0.0 & 0.0 \\
\hline & D & $\Delta \mathrm{r}$ & 1.302 & 1.299 & 1.299 & 1.299 & 1.300 & 1.299 \\
\hline & & DA & -51.4 & 0.0 & 0.0 & 0.0 & 17.6 & -16.3 \\
\hline & A & $\Delta \mathrm{r}$ & 1.292 & 1.296 & 1.295 & 1.295 & 1.297 & 1.295 \\
\hline \multirow{4}{*}{ ARHH } & $\mathbf{y}$ & DA & -37.76 & 0.0 & 0.0 & 0.0 & 0.0 & 0.0 \\
\hline & $\mathbf{Y}$ & $\Delta \mathrm{r}$ & 1.286 & 1.283 & 1.289 & 1.289 & 1.291 & 1.291 \\
\hline & $\mathbf{X}$ & DA & 0.0 & -34.4 & 0.0 & 13.9 & 17.9 & 20.6 \\
\hline & 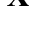 & $\Delta \mathrm{r}$ & 1.280 & 1.284 & 1.282 & 1.282 & 1.284 & 1.284 \\
\hline
\end{tabular}<smiles>CN(C)c1ccc(N=Nc2cccc(C(=O)O)c2)cc1</smiles>

A<smiles>[X]c1ccc(N=Nc2ccc(C(=O)O)cc2)cc1</smiles>

$\mathbf{X}$
B<smiles>[Y]=C(N=[NH+]c1ccc([NH2+][CH2-])cc1)c1cccc(C(=O)O)c1</smiles>

benzene ring. It is interesting to notice anionic properties of $p$-MRA. The bond length turns out similar, and dihedral angles are weakly tilted in both methods. The free energy for $p$-MR is the lowest among three isomers, i.e., $p$-MRA $<m$ MRA $<o$-MRA as shown in Table 3. This implies that the a carboxylate group is not strong meta-director in anionic 4amino-trans-azobenzene system, and assists molecular conjugation better at para-position.

Conformations of neutral MR isomers and MY. In Table 2 and Table 3, computational results of neutral species of $o$-MR, $m$-MR, $p$-MR and MY are listed. Neutral species of all four hold planar conformations in both methods 
Table 3. Calculated $\Delta \mathrm{E}_{\mathrm{c}}$ and $\Delta \mathrm{G}_{\mathrm{T}}$ of de-protonated species (o-MRA, $m$-MRA, and $p$-MRA) and neutral species (o-MR, $m$-MR, $p$-MR, and MY). (More stable rotamers are written in Bold.)

\begin{tabular}{|c|c|c|c|c|c|}
\hline & & & & & \\
\hline \multirow[b]{2}{*}{$o$-MRA } & & $C(18)-$ & $C(17)-$ & $C(18)-$ & $C(17)-$ \\
\hline & $\begin{array}{l}\Delta \mathrm{E}_{\mathrm{c}} \\
\Delta \mathrm{G}_{\mathrm{T}}\end{array}$ & $\begin{array}{l}-894.519053 \\
-894.567270\end{array}$ & $\begin{array}{l}-894.515806 \\
-894.564316\end{array}$ & $\begin{array}{l}-894.534965 \\
-894.583132\end{array}$ & $\begin{array}{l}-894.532157 \\
-894.581660\end{array}$ \\
\hline \multirow[b]{2}{*}{$m$-MRA } & & $C(25)-$ & $C(26)-$ & $C(25)-$ & $C(26)-$ \\
\hline & $\begin{array}{l}\Delta \mathrm{E}_{\mathrm{c}} \\
\Delta \mathrm{G}_{\mathrm{T}}\end{array}$ & $\begin{array}{l}-894.530940 \\
-894.579429\end{array}$ & $\begin{array}{l}-894.529670 \\
-894.578606\end{array}$ & $\begin{array}{l}\mathbf{- 8 9 4 . 5 4 3 9 0 2} \\
-894.592989\end{array}$ & $\begin{array}{l}-894.542722 \\
\mathbf{- 8 9 4 . 5 9 3 1 1 3}\end{array}$ \\
\hline$p$-MRA & $\begin{array}{l}\Delta \mathrm{E}_{\mathrm{c}} \\
\Delta \mathrm{G}_{\mathrm{T}}\end{array}$ & \multicolumn{2}{|c|}{$\begin{array}{l}-894.532391 \\
-894.581338\end{array}$} & \multicolumn{2}{|c|}{$\begin{array}{l}-894.546829 \\
-894.596292 \\
\end{array}$} \\
\hline & & \multicolumn{2}{|c|}{ B3LYP/6-31+G* } & \multicolumn{2}{|c|}{ BP86/6-31+G* } \\
\hline \multirow[b]{2}{*}{$o$-MR } & & $C(18)-$ & $C(17)-$ & $C(18)-$ & $C(17)-$ \\
\hline & $\begin{array}{l}\Delta \mathrm{E}_{\mathrm{c}} \\
\Delta \mathrm{G}_{\mathrm{T}}\end{array}$ & $\begin{array}{l}-895.060789 \\
-895.109748\end{array}$ & $\begin{array}{l}-895.052997 \\
-895.101712\end{array}$ & $\begin{array}{l}-895.074542 \\
-895.123729\end{array}$ & $\begin{array}{l}-895.068027 \\
-895.116736\end{array}$ \\
\hline \multirow[b]{2}{*}{$m$-MR } & & $C(25)-$ & $C(26)-$ & $C(25)-$ & $C(26)-$ \\
\hline & $\begin{array}{l}\Delta \mathrm{E}_{\mathrm{c}} \\
\Delta \mathrm{G}_{\mathrm{T}}\end{array}$ & $\begin{array}{l}-895.062283 \\
-895.112548\end{array}$ & $\begin{array}{l}-895.061814 \\
-895.111790\end{array}$ & $\begin{array}{l}-895.072304 \\
-895.121818\end{array}$ & $\begin{array}{l}-895.071817 \\
-895.121574\end{array}$ \\
\hline$p$-MR & $\begin{array}{l}\Delta \mathrm{E}_{\mathrm{c}} \\
\Delta \mathrm{G}_{\mathrm{T}}\end{array}$ & \multicolumn{2}{|c|}{$\begin{array}{l}-895.063155 \\
-895.112813\end{array}$} & \multicolumn{2}{|c|}{$\begin{array}{l}-895.073511 \\
-895.123423\end{array}$} \\
\hline MY & $\begin{array}{l}\Delta \mathrm{E}_{\mathrm{c}} \\
\Delta \mathrm{G}_{\mathrm{T}}\end{array}$ & \multicolumn{2}{|c|}{$\begin{array}{l}-706.494374 \\
-706.537768\end{array}$} & \multicolumn{2}{|c|}{$\begin{array}{l}-706.494718 \\
-706.540517\end{array}$} \\
\hline
\end{tabular}

reflecting strong delocalization of molecular $\pi$-electron system. (cf. Listed values of $o$-MR in Table 2 and 3 are from conformer $\mathbf{1}$ and $\mathbf{6}$ in Table 1 incorporating internal hydrogen bonds.) The distances of $\mathrm{N}=\mathrm{N}$ bonds turn out to $p$ $\mathrm{MR} \approx o-\mathrm{MR}($ with $\mathrm{HB})>m-\mathrm{MR}>\mathrm{MY} \approx o-\mathrm{MR}$ (without
HB). The carboxyl group exercises its effects strongly through para-substitution of MY. This suggests that neutral $p$-MR is effectively stabilized on the resonance via canonical structures, presumably including zwitterion forms.

Conformations of monocationic MRH isomers and

Table 4. Calculated $\Delta \mathrm{E}_{\mathrm{c}}$ and $\Delta \mathrm{G}_{\mathrm{T}}$ of mono-protonated species (o-MRH, $m$-MRH, $p$-MRH, and MYH). (More stable rotamers or species are written in Bold.)

\begin{tabular}{|c|c|c|c|c|c|c|}
\hline & & & \multicolumn{2}{|c|}{ B3LYP/6-31+G* } & \multicolumn{2}{|c|}{ BP86/6-31+G* } \\
\hline \multirow{3}{*}{$o$-MRH } & & & $C(18)-$ & $C(17)-$ & $C(18)-$ & $C(17)-$ \\
\hline & B & $\begin{array}{l}\Delta \mathrm{E}_{\mathrm{c}} \\
\Delta \mathrm{G}_{\mathrm{T}}\end{array}$ & $\begin{array}{l}-895.443869 \\
-895.491713\end{array}$ & $\begin{array}{l}-895.424364 \\
-895.472724\end{array}$ & $\begin{array}{l}-895.457339 \\
-895.505737\end{array}$ & $\begin{array}{l}-895.437035 \\
-895.486363\end{array}$ \\
\hline & $\mathbf{A}$ & $\begin{array}{l}\Delta \mathrm{E}_{\mathrm{c}} \\
\Delta \mathrm{G}_{\mathrm{T}}\end{array}$ & $\begin{array}{l}-895.419729 \\
-895.467825\end{array}$ & $\begin{array}{r}-895.433078 \\
-895.480540\end{array}$ & $\begin{array}{l}-895.436060 \\
-895.484680\end{array}$ & $\begin{array}{l}-895.449521 \\
-895.497525\end{array}$ \\
\hline \multirow{3}{*}{$m$-MRH } & & & $C(25)-$ & $C(26)-$ & $C(25)-$ & $C(26)-$ \\
\hline & B & $\begin{array}{l}\Delta \mathrm{E}_{\mathrm{c}} \\
\Delta \mathrm{G}_{\mathrm{T}}\end{array}$ & $\begin{array}{l}-895.434199 \\
-895.482827\end{array}$ & $\begin{array}{l}-895.433179 \\
-895.481679\end{array}$ & $\begin{array}{l}-895.447058 \\
-895.496475\end{array}$ & $\begin{array}{l}-895.445975 \\
-895.495155\end{array}$ \\
\hline & $\mathbf{A}$ & $\begin{array}{l}\Delta \mathrm{E}_{\mathrm{c}} \\
\Delta \mathrm{G}_{\mathrm{T}}\end{array}$ & $\begin{array}{l}-895.425131 \\
-895.474476\end{array}$ & $\begin{array}{l}\mathbf{8 9 5 . 4 2 7 0 3 9} \\
-895.476629 \\
\end{array}$ & $\begin{array}{l}-895.440217 \\
\mathbf{- 8 9 5 . 4 9 0 0 5 2}\end{array}$ & $\begin{array}{l}\mathbf{- 8 9 5 . 4 4 2 1 8 8} \\
-895.489047\end{array}$ \\
\hline \multirow{2}{*}{$p$-MRH } & B & $\begin{array}{l}\Delta \mathrm{E}_{\mathrm{c}} \\
\Delta \mathrm{G}_{\mathrm{T}}\end{array}$ & \multicolumn{2}{|c|}{$\begin{array}{l}-895.432779 \\
-895.481378\end{array}$} & \multicolumn{2}{|c|}{$\begin{array}{l}-895.445774 \\
-895.495128\end{array}$} \\
\hline & $\mathbf{A}$ & $\begin{array}{l}\Delta \mathrm{E}_{\mathrm{c}} \\
\Delta \mathrm{G}_{\mathrm{T}}\end{array}$ & \multicolumn{2}{|c|}{$\begin{array}{l}-895.424416 \\
-895.473081\end{array}$} & \multicolumn{2}{|c|}{$\begin{array}{l}-895.439973 \\
-895.489203\end{array}$} \\
\hline \multirow{2}{*}{ MYH } & B & $\begin{array}{l}\Delta \mathrm{E}_{\mathrm{c}} \\
\Delta \mathrm{G}_{\mathrm{T}}\end{array}$ & \multicolumn{2}{|c|}{$\begin{array}{r}-706.869629 \\
-706.913842\end{array}$} & \multicolumn{2}{|c|}{$\begin{array}{l}-706.872959 \\
-706.917844\end{array}$} \\
\hline & $\mathbf{A}$ & $\begin{array}{l}\Delta \mathrm{E}_{\mathrm{c}} \\
\Delta \mathrm{G}_{\mathrm{T}}\end{array}$ & \multicolumn{2}{|c|}{$\begin{array}{l}-706.862451 \\
-706.906863\end{array}$} & \multicolumn{2}{|c|}{$\begin{array}{l}-706.867778 \\
-706.912438\end{array}$} \\
\hline
\end{tabular}


MYH. Computational results of mono-protonated species of $o$-MRH, $m$-MRH, $p$-MRH and MYH are listed in Table 2 and Table 4. Two structures B (carboxyl attached at $\beta$-azo nitrogen) and $\mathrm{A}$ (at $\alpha$-azo) are compared. The energy of species B is lower than of A, which is in good agreement with previous observations. ${ }^{17}$ Between two rotamers of $o$ MRH (carboxyl group attaching to $\mathrm{C}(18)$ or to $\mathrm{C}(17)$, cf. in Figure 1) and of $m$-MRH(carboxyl group attaching $\mathrm{C}(25)$ and (C26)), a rotamer $\mathrm{C}(18)$ for $o-\mathrm{MRH}$ and a rotamer $\mathrm{C}(25)$ for $m$-MRH are lower than corresponding rotamers. These conformers, $p$-MRH and MYH are extended about $0.02 \AA$ in distances of $\mathrm{N}=\mathrm{N}$ bonds from neutral which was examined via frequency shift in Raman spectroscopic method previously. ${ }^{18,20}$ These are all planar showing particular delocalization under both methods over whole ionic structure. It is well understood that the quinonoid structure represented to a form IIb in a scheme of the protonation equilibria in Figure 2 contributes to the resonance principally for these species. Carboxyl substitution on MYH contributes some degrees of stabilization for cationic species at $o-, m$ - or $p$ - position. The mono-protonated species at the amino nitrogen was identified in NMR study, ${ }^{18 \mathrm{~b}}$ but its calculated energy is so high and twist for $o$-MR, and planar for $m$-MR, so not displayed in Table.

Conformations of dicationic MRHH isomers and MYHH. In the Table 2 and Table 5, computational results of di-protonated species of $o$-MRHH, $m$-MRHH, $p$-MRHH and $\mathrm{MYHH}$ are listed. There are two structures $\mathrm{Y}$ and $\mathrm{X}$ configuring the positions of two protons attached at amino and $\alpha$-azo and the other at amino and $\beta$-azo nitrogen atoms, respectively. Species Y is lower in all circumstances than X. One thing we ought to notice is that the other corresponding rotamer is lower as summarized in Table 2 which is different to the cases of MRH. This could be explained via canonical forms VIa and VIb in Figure 2. Studies ${ }^{21}$ of methyl orange ( $p$-dimethylaminoazobenene sulfonate) using Raman spectroscopy or 4-aminoazobenzene using NMR spectroscopy had demonstrated that dicationic species takes di-

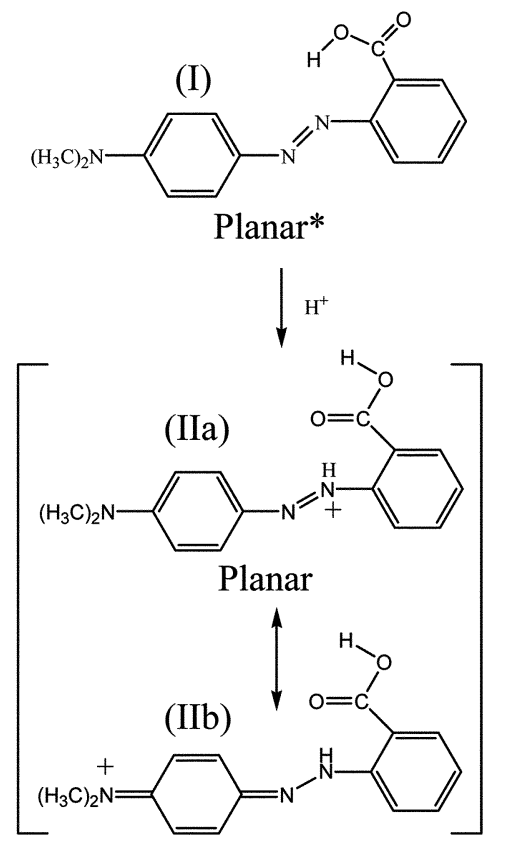

Planar

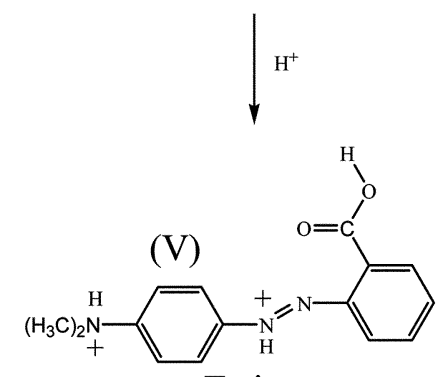

Twist

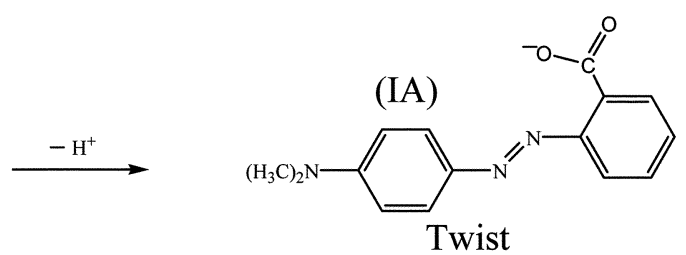

Twist

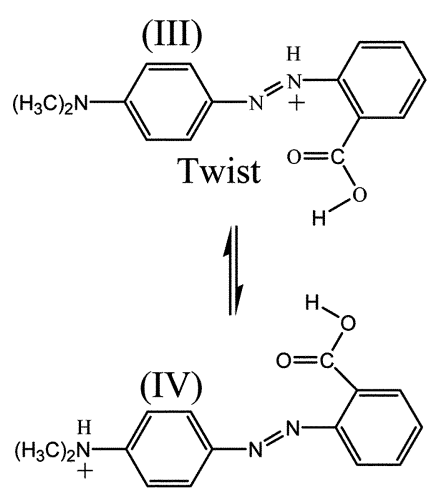

Twist

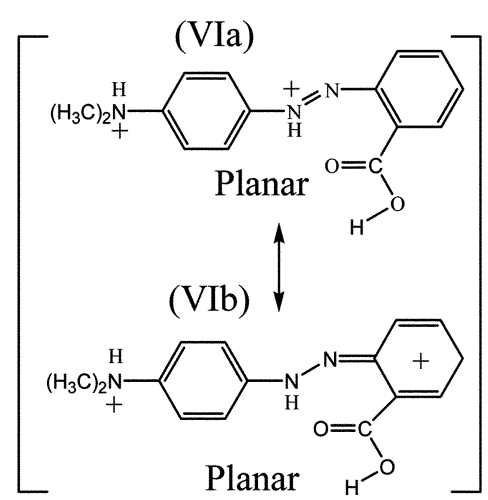

Figure 2. Protonation Equilibria of $o$-MR. (* Species (I) without internal hydrogen bonding would be twist as shown in Table 1.) 
Table 5. Calculated $\Delta \mathrm{E}_{\mathrm{c}}$ and $\Delta \mathrm{G}_{\mathrm{T}}$ of di-protonated species (o-MRHH, $m-\mathrm{MRHH}, p$-MRHH, and MYHH). (More stable rotamers or species are written in Bold.)

\begin{tabular}{|c|c|c|c|c|c|c|}
\hline & & & B3L & $1+\mathrm{G}^{*}$ & BP8 & $+\mathrm{G}^{*}$ \\
\hline \multirow{3}{*}{$o-\mathrm{MRHH}$} & & & $C(18)-$ & $C(17)-$ & $C(18)-$ & $C(17)-$ \\
\hline & $\mathbf{Y}$ & $\begin{array}{l}\Delta \mathrm{E}_{\mathrm{c}} \\
\Delta \mathrm{G}_{\mathrm{T}}\end{array}$ & $\begin{array}{l}-895.654972 \\
-895.703258\end{array}$ & $\begin{array}{l}-895.673009 \\
-895.720643\end{array}$ & $\begin{array}{l}-895.665998 \\
-895.713992\end{array}$ & $\begin{array}{l}-895.683468 \\
-895.731683 \\
\end{array}$ \\
\hline & $\mathbf{X}$ & $\begin{array}{l}\Delta \mathrm{E}_{\mathrm{c}} \\
\Delta \mathrm{G}_{\mathrm{T}}\end{array}$ & $\begin{array}{l}-895.669972 \\
-895.716916\end{array}$ & $\begin{array}{l}-895.657540 \\
-895.705949\end{array}$ & $\begin{array}{l}-895.680867 \\
-895.728620\end{array}$ & $\begin{array}{l}-895.657864 \\
-895.706305\end{array}$ \\
\hline \multirow{3}{*}{$m$-MRHH } & & & $C(25)-$ & $C(26)-$ & $C(25)-$ & $C(26)-$ \\
\hline & $\mathbf{Y}$ & $\begin{array}{l}\Delta \mathrm{E}_{\mathrm{c}} \\
\Delta \mathrm{G}_{\mathrm{T}}\end{array}$ & $\begin{array}{l}-895.659765 \\
-895.707690\end{array}$ & $\begin{array}{l}-895.661471 \\
-895.709939\end{array}$ & $\begin{array}{l}-895.668327 \\
-895.716702\end{array}$ & $\begin{array}{l}-895.670174 \\
-895.719255\end{array}$ \\
\hline & $\mathbf{X}$ & $\begin{array}{l}\Delta \mathrm{E}_{\mathrm{c}} \\
\Delta \mathrm{G}_{\mathrm{T}}\end{array}$ & $\begin{array}{l}-895.654682 \\
-895.703381\end{array}$ & $\begin{array}{l}-895.654062 \\
-895.700345\end{array}$ & $\begin{array}{l}-895.665121 \\
-895.714365\end{array}$ & $\begin{array}{l}-895.664489 \\
-895.713820\end{array}$ \\
\hline \multirow{2}{*}{$p$-MRHH } & $\mathbf{Y}$ & $\begin{array}{l}\Delta \mathrm{E}_{\mathrm{c}} \\
\Delta \mathrm{G}_{\mathrm{T}}\end{array}$ & \multicolumn{2}{|c|}{$\begin{array}{l}-895.657377 \\
-895.706072\end{array}$} & \multicolumn{2}{|c|}{$\begin{array}{l}-895.666890 \\
-895.716541\end{array}$} \\
\hline & $\mathbf{X}$ & $\begin{array}{l}\Delta \mathrm{E}_{\mathrm{c}} \\
\Delta \mathrm{G}_{\mathrm{T}}\end{array}$ & \multicolumn{2}{|c|}{$\begin{array}{l}-895.651660 \\
-895.700646\end{array}$} & \multicolumn{2}{|c|}{$\begin{array}{l}-895.662844 \\
-895.712519\end{array}$} \\
\hline \multirow{2}{*}{ MYHH } & $\mathbf{Y}$ & $\begin{array}{l}\Delta \mathrm{E}_{\mathrm{c}} \\
\Delta \mathrm{G}_{\mathrm{T}}\end{array}$ & \multicolumn{2}{|c|}{$\begin{array}{l}-707.099245 \\
-707.143205\end{array}$} & \multicolumn{2}{|c|}{$\begin{array}{l}-707.097891 \\
-707.142325\end{array}$} \\
\hline & $\mathbf{X}$ & $\begin{array}{l}\Delta \mathrm{E}_{\mathrm{c}} \\
\Delta \mathrm{G}_{\mathrm{T}}\end{array}$ & \multicolumn{2}{|c|}{$\begin{array}{l}-707.092733 \\
-707.136906\end{array}$} & \multicolumn{2}{|c|}{$\begin{array}{l}-707.093395 \\
-707.137833\end{array}$} \\
\hline
\end{tabular}

protonated form at amino and $\alpha$-azo nitrogen atoms. This calculation also supports that the same pattern may be applied to 4-amino-trans-azobenzene derivative such as MR or MY. ${ }^{18}$ Raman spectroscopic studies of $o$-MRHH had shown that the azo character was regained and strong stretching vibrational frequencies characteristic of $\mathrm{C}=\mathrm{C}$ bond was obtained in the region of about 1600 to $1630 \mathrm{~cm}^{-1}$. Calculations also display the contraction of the distances of $\mathrm{N}=\mathrm{N}$ bonds. For example, $1.289 \AA$ to $1.268 \AA$ for $o-\mathrm{MRHH}$, $1.286 \AA$ to $1.275 \AA$ for $m$-MTHH, $1.287 \AA$ to $1.276 \AA$ for $p$ MRHH from B3LYP method. The same trends may be seen from BP86 method in Table 2. Furthermore, these species are all planar from both methods, but a rotamer $\mathrm{V}$ in Figure 2 is twist and rather higher in energy. Even though the $\mathrm{N}=\mathrm{N}$ bond length in MRHH is contracted from MRH, the geometry is still planar. A form VIb could be realized from the existence of strong $\mathrm{C}=\mathrm{C}$ stretching frequencies in Raman spectroscopy. The structure of MRHH can be explained on the resonance of canonical forms VIa and VIb in Figure 2, and that character of a form VIa is more likely dominant than VIb considering a contraction of $\mathrm{N}=\mathrm{N}$ bond lengths.

\section{Conclusions}

Substitution of a carboxyl group at $m$ - or $p$-position on 4aminoazobenzene structure shows better conjugation across the whole molecular system. As a result, species IA, III, IV and V in Figure 2 are planar or weakly tilted for $m$-MR or $p$ $\mathrm{MR}$, others the same as $o$-MR. Neutral $o$-MR possesses a capability of intra-molecular hydrogen bonding, which causes the geometry planar, otherwise twist. Neutral $m-, p$ MR and MY are planar even though they can not form internal hydrogen bonds. For mono-protonated species of MR or MY, a proton is attached to $\beta$-azo nitrogen atom, and planar. This monocationic species loses its azo character a bit, and shows strong delocalization of $\pi$-electronic system characterized as a quinonoid canonical form. Calculations reveal that di-protonated species of MR or MY holds two protons at the amino and $\alpha$-azo nitrogen atoms, and planar. This species regains its azo character, but displays strongly delocalized electronic property in terms of carbocationic canonical forms. These results correspond well with Raman spectroscopic observations of dicationic MRHH species. ${ }^{18}$ The carboxyl substitution on 4-aminoazobenzene structure has some degrees of effects on the delocalization whether a species is neutral, mono-, di- or de-protonated.

Acknowledgement. This work was supported by Chungbuk National University Grant in 2005. Also, we acknowledge Brain Korea 21 Program of the Ministry of Education and Human Resources Development, Korea for the financial support.

\section{References}

1. (a) Ucar, M.; Solak, A. O.; Menek, N. Anal. Sci. 2002, 18, 997. (b) Ucar, M.; Solak, A. O.; Aksu, M. L.; Toy, M. Turk. J. Chem. 2002, 26,509 .

2. Barek, J.; Cvačka, J.; Muck, A.; Quaiserová, V.; Zima, J. Fresenius' J. Anal. Chem. 2001, 369, 556.

3. Terazima, M.; Okamoto, K.; Hirota, N. J. Phys. Chem. 1993, 97, 5188.

4. (a) Park, S.-K.; Lee, C.-K.; Lee, S.-H.; Lee, N.-S. Bull. Korean Chem. Soc. 2002, 23, 253. (b) Park, S.-K.; Lee, N.-S.; Lee, S.-H. Bull. Korean Chem. Soc. 2000, 21, 959.

5. (a) Kim, S. H.; Kim, S. K. Bull. Korean Chem. Soc. 1996, 17, 365. 
(b) Kim, S. H.; Kim, S. K.; Choi, M.; Kim, H. Bull. Korean Chem. Soc. 1996, 17, 217.

6. Brianso, J. L.; Solans, X.; Vicente, J. J. Chem. Soc. Dalton Trans. 1983, 169.

7. Simoni, F.; Lucchetti, L.; Lucchetta, D. E.; Francescangeli, O. Opt. Express 2001, 9, 85.

8. Shih, M. Y.; Shishido, A.; Khoo, I. C. Opt. Lett. 1997, 22, 1424.

9. (a) Moreiras, D.; Sloans, J.; Sloans, X.; Miravitlles, C.; German, G.; Declercq, J. P. Cryst. Struct. Commun. 1980, 9, 921. (b) Bouwstra, J. A.; Schouten, A.; Kroon, J. Acta Crystallogr. Sect. C 1983, 39, 1121.

10. Sasaki, C.; Kitoh, S.-I.; Yamada, K.; Hayashi, H.; Kunimoto, K.K. Anal. Sci. 2004, 20, x117.

11. Sasaki, C.; Kitoh, S.-I.; Yamada, K.; Kunimoto, K.-K.; Maeda, S.; Kuwae, A.; Hanai, K. Anal. Sci. 2003, 19, x1.

12. Park, H. S.; Sung, J.; Chang, T. Macromolecules 1996, 29, 3216.

13. Lee, J.; Park, K.; Chang, T.; Jung, J. C. Macromolecules 1992, 25 , 6977.

14. Park, H. S.; Oh, K. S.; Kim, K. S.; Chang, T.; Spiegel, D. R. J. Phys. Chem. B 1999, 103, 2355.

15. Rottman, C.; Turniansky, A.; Avnir, D. J. Sol-Gel Sci. Technol. 1998, 13, 17.

16. Bachackashvilli, A.; Katz, B.; Priel, Z.; Efrima, S. J. Phys. Chem. 1984, 88, 6185

17. (a) Machida, K.; Lee, H.; Kuwae, A. J. Raman Spectrosc. 1980, 9 , 198. (b) Machida, K.; Lee, H.; Uno, T. J. Raman Spectrosc. 1978, 7, 184. (c) Uno, T.; Lee, H.; Saito, Y.; Machida, K. Spectrochim. Acta 1976, 32A, 1319. (d) Lee, H.; Machida, K.; Kuwae, A.; Harada, I. J. Raman Spectrosc. 1983, 14, 126.

18. (a) Park, S.-K.; Lee, C.; Min, K.-C.; Lee, N.-S. Bull. Korean Chem. Soc. 2004, 25, 1817. (b) Park, S.-K. Ph.D. dissertation, Chungbuk National University, 2005.
19. (a) Bisset, A.; Dines, T. J. J. Chem. Soc. Faraday Trans. 1995, 91 , 499. (b) Bisset, A.; Dines, T. J. J. Raman Spectrosc. 1995, 26, 791. (c) Bisset, A.; Dines, T. J. J. Chem. Soc. Faraday Trans. 1997, 93, 1629.

20. Bell, S.; Bisset, A.; Dines, T. J. J. Raman Spectrosc. 1998, 29, 447.

21. (a) Lee, H.; Machida, K.; Kuwae, A.; Saito, Y. J. Mol. Struct 1980, 68, 51. (b) Kuroda, Y.; Lee, H.; Kuwae, A. J. Phys. Chem. 1980, 84, 3417.

22. Koch, W.; Holthausen, M. C. A Chemist's Guide to Density Functional Theory; Wiley-VCH: Weinheim, 2000.

23. Biswas, N.; Umapathy, S. J. Phys. Chem. A 1997, 101, 5555.

24. (a) Han, Y.-K.; Lee, S. U. Bull. Korean Chem. Soc. 2005, 26, 43. (b) Lee, S. Y. Bull. Korean Chem. Soc. 2004, 25, 1855.

25. Frisch, M. J.; Trucks, G. W.; Schlegel, H. B.; Scuseria, G. E.; Robb, M. A.; Cheeseman, J. R.; Montgomery, Jr., J. A.; Vreven, T.; Kudin, K. N.; Burant, J. C.; Millam, J. M.; Iyengar, S. S.; Tomasi, J.; Barone, V.; Mennucci, B.; Cossi, M.; Scalmani, G.; Riga, N.; Petersson, G. A.; Nakatsuji, H.; Hada, M.; Ehara, M.; Toyoda, K.; Fukuda, R.; Hasegawa, J.; Ishida, M.; Nakajima, T.; Honda, Y.; Kitao, O.; Nakai, H.; Klene, M.; Li, X.; Knox, J. E.; Hratchian, H. P.; Cross, J. B.; Adamo, C.; Jaramillo, J.; Gomperts, R.; Stratmann, R. E.; Yazyev, O.; Austin, A. J.; Cammi, R.; Pomelli, C.; Ochterski, J. W.; Ayala, P. Y.; Morokuma, K.; Voth, G. A.; Salvador, P.; Dannenberg, J. J.; Zakrzewski, V. G. Dapprich, S.; Daniels, A. D.; Strain, M. C.; Farkas, O.; Malick, D. K.; Rabuck, A. D.; Raghavachari, K.; Foresman, J. B.; Ortiz, J. V.; Cui, Q.; Baboul, A. G.; Clifford, S.; Cioslowski, J.; Stefanov, B. B.; Liu, G.; Liashenko, A.; Piskorz, P.; Komaromi, I.; Martin, R. L.; Fox, D. J.; Keith, T.; Al-Laham, M. A.; Peng, C. Y.; Nanayakkara, A.; Challacombe, M.; Gill, P. M. W.; Johnson, B.; Chen, W.; Wong, M. W.; Gonzalez, C.; Pople, J. A. Gaussian 03, Revision A.1; Gaussian, Inc.: Pittsburgh, PA, 2003. 